\title{
Putting machine learning to use in natural resource management- improving model performance
}

\author{
Ulrich J. Frey $^{1}$
}

\begin{abstract}
Machine learning models have proven to be very successful in many fields of research. Yet, in natural resource management, modeling with algorithms such as gradient boosting or artificial neural networks is virtually nonexistent. The current state of research on existing applications of machine learning in the field of social-ecological systems is outlined in a systematic literature review. For this purpose, a short introduction on fundamental concepts of neural network modeling is provided. The data set used, a prototypical case study collection of social-ecological systems - the common-pool resources database from the Ostrom Workshop-is described. I answer the question of whether neural networks are suitable for the kind of data and problems in this field, and whether they or other machine learning algorithms perform better than standard statistical approaches such as regressions. The results indicate a large performance gain. In addition, I identify obstacles for adapting machine learning and provide suggestions on how to overcome them. By using a freely available data set and open source software, and by providing the full code, I hope to enable the community to add machine learning to the existing tool box of statistical methods.
\end{abstract}

Key Words: comparability; gradient boosting; machine learning; natural resource management; neural networks; social-ecological systems

\section{INTRODUCTION}

By now, machine learning algorithms have proven themselves as powerful problem-solving tools in many domains. Examples include complex strategy games like chess and Go (Silver et al. 2017), strategic decisions under uncertainty against human players - e.g., poker (Brown and Sandholm 2019) — or complex cooperative games (Mnih et al. 2015). Other areas include autonomous driving, translations in many languages via a universal interlingua (Johnson et al. 2017), and image recognition (multiclass object detection) in the millisecond range, beating human performance (Le et al. 2012, Girshick 2015).

For many scientific domains, the question arises as to whether and how these advances in machine learning can be applied to their own research questions. It has become apparent that application of machine learning algorithms varies greatly between individual disciplines. In particular, in the fields of natural resource management and social-ecological systems it seems that machine learning methods are still used rather infrequently. However, applying machine learning algorithms to natural resource management problems may result in various benefits: improving explanatory power for many models - thus, for example, being better able to distinguish important from irrelevant factors for successful management; generating more robust results by using different algorithms with the same workflow (see Discussion), and finally, providing an extension to the toolbox of methods for analyzing case studies.

Given that machine learning algorithms have demonstrated their potential for modeling in many fields (LeCun et al. 2015), I aim to estimate the potential of machine learning methods, especially deep neural networks, for modeling natural resource systems. I evaluate the general suitability or unsuitability in both theory (through a literature review) and practice (a systematic search for neural network architectures for a typical data set). By assessing the potential of machine learning in natural resource research and by summarizing the state of research and best practices as well as directions, future research may profit. Such evaluations have also been done for other research fields such as biology and medicine (Ching et al. 2018).

The next section of this article outlines the state of research on existing applications of machine learning in the fields of socialecological systems, (community-based) natural resource management, and common-pool resources in order to assess for which problems other authors have applied machine learning methods.

The Data section describes the data set used, a prototypical case study collection from social-ecological systems - the commonpool resources database from the Ostrom Workshop $(n=122)$. In the Results section, I discuss whether deep neural networks perform better than other methods in terms of model quality (goodness-of-fit). By comparing different architectures, it will become clear which kinds of networks may serve as a base for improved models in the future. After that, in the Discussion, I review whether neural networks could indeed be a methodological step forward in the area of natural resource management.

The Methods section provides a short introduction on fundamental concepts of neural network modeling in order to facilitate future analyses. A prototypical data set is analyzed by using many different variations (architectures) of neural networks to establish the general suitability of this method for natural resource management data.

To make the agenda more concrete, I strive to answer three research questions, in particular: "

1. Can shallow or deep neural networks achieve a decisive improvement in model quality compared to previously employed statistical techniques such as linear regressions?" 
2. Are there architectures that are particularly suited for the analysis of social-ecological systems?"

3. Are other machine learning methods suited to deal with social-ecological case study collections?

\section{State of research}

One of my goals was to evaluate whether and how machine learning methods have already been used in the fields of natural resource management and social-ecological systems (e.g., Humphries et al. 2018). Hence, in order to gain an overview, a systematic literature analysis was conducted on 19-21 November 2019 and 23 November 2020. A keyword search was conducted in more general journals-Nature, Science, Proceedings of the National Academy of Sciences of the United States of America, Proceedings of the Royal Society, Nature Methods, Nature Sustainability, Nature Climate Change, and PLoS ONE - and in journals that are central to natural resource management (Ecology \& Society, Sustainability Science, International Journal of the Commons, Ecological Modeling, Global Environmental Change, Journal of Environmental Management, World Development, Environmental Modeling and Software, and Journal of Cleaner Production). The search was conducted using the internal search engines of each journal.

The keywords that were searched for were "machine learning", "neural network", and "deep learning". For the more general journals, which, in contrast to the topic-specific journals, are not restricted to natural resources, I added to each of the three search terms the keywords "natural resource" or "social ecological". Using no quotation marks on both search terms resulted in thousands of irrelevant hits (e.g., on learning); using them for both search terms simultaneously was too restrictive and resulted in 0 hits. Some journal search engines interpreted phrases in quotation marks as logical "ORs", which resulted in many irrelevant hits (e.g., "machine learning" as machine OR learning).

The exact figures for each search combination are provided in Table A1. Typically, searches produced $20-150$ hits. These were screened. If a hit seemed to be about any topic in natural resource management and used any kind of machine learning techniques, it was included in the final data set (Table A2). Of course, many other machine learning classifiers and algorithms exist (Elith et al. 2006, Fernández-Delgado et al. 2014). However, I was concerned with only the most widely used algorithms - neural networks, gradient boosting, and generalized linear modelssince even they are rarely used for natural resource management problems.

All in all, very few hits were found. Although the first screening resulted in $n=2.616$ hits for topic-specific journals and 3.287 for more general journals, only 32 papers were about applying machine learning to natural resources in any way. This was rather surprising given the spectacular advances in other fields. This number proves that machine learning does not yet play a role in natural resource management. I discuss possible reasons for this in the Discussion section.

Before discussing the few relevant papers, I note that in many adjacent research fields such as renewable energies (IPCC 2018) or biodiversity research, machine learning methods, in particular neural networks, are used quite frequently. Typical fields of application include, but are not limited to, wind energy potential assessment, species biodiversity models, expansion models of species, spatial habitat modeling, evaluation of remote sensing data, and prediction of solar radiation.

One of the first applications of neural networks for socialecological systems was provided by Frey and Rusch $(2013,2014)$. For common-pool resources case studies, shallow neural networks are used to identify success factors. These papers also substantiate the claim often made that neural networks are able to cope better with nonlinearities between features than are regressions (Paruelo and Tomasel 1997). Very similar is the attempt to identify success patterns in fisheries with random forests (Gutiérrez et al. 2011).

Among other uses of machine learning, two prominent topics for applying machine learning are modeling land use change (Cao et al. 2019, Saputra and Lee 2019; for land use change in rivers, see Álvarez-Romero et al. 2015, Magierowski et al. 2015; for classifying habitats, see Václavik et al. 2013), as well as predicting and classifying fishermen behavior (Jules Dreyfus-León 1999, Cenek and Franklin 2017, Crespo et al. 2018, O'Farrell et al. 2019). For further details on these studies, see Table A 2 and the Literature Cited section.

All in all, neural networks and random forests were the most popular techniques, while content-wise, predictive tasks for spatial patterns dominated. However, there were no commonly adopted workflows or any other kind of standards across papers.

Given these few existing attempts to make machine learning fruitful for natural resource topics, it is even more important to explore in practice whether neural networks can improve model quality. I therefore implemented many neural network architectures to explore this potential in more detail.

\section{Data}

The common-pool resources database was chosen for the test of neural networks and the method comparison described in the State of research section. It is a typical data set consisting of case studies of irrigation systems and fisheries $(n=122)$, and is available online (https://seslibrary.asu.edu/cpr). The idea is that it can stand for hundreds of other data sets that have a similar structure concerning number of variables, tabular structure, and concepts involved. Reference data sets are well-known from other fields, one famous example being the MNIST data set (http:// yann.lecun.com/exdb/mnist/), which serves as a benchmark for comparing performance of machine learning classifiers. In contrast to other data sets outside natural resource management, it is relatively small, but differences between cases are rather large, which means that pattern recognition via supervised learning is particularly suitable.

The structure of the common-pool resources database was developed at the Ostrom Workshop in Political Theory and Policy Analysis at University Indiana Bloomington. The data have been collected for several years and are the basis for perhaps the most influential analysis on social-ecological systems, Governing the Commons (Ostrom 1990). The database comprises about 500 variables that include demographic, geographical, social, cultural, climatic, economic, and technical details of irrigation systems and fisheries worldwide. 
There were several reasons for selecting this data set. First, analyses have shown that the data set is typical for socialecological case studies (Frey 2018). Second, it has a sufficient number of heterogenous cases.

The 593 variables were aggregated; i.e., assigned to 24 abstract concepts, such as social capital, resource size, or participation opportunities. The details of assigning the variables to these concepts can be found in Frey (2018). One benefit of aggregating is that missing variables are no longer problematic, since existing variables within a concept can stand in for variables that are missing.

The dependent variable was ecological success. The variables it is composed of can be found in Table A4. All variables were normalized with zero mean and unit variance. This is a common step in data preparation for neural networks to avoid the problems of exploding and vanishing gradients.

\section{METHODS}

Given that neural networks usually work with thousands or even millions of data records, one important question to be answered first is whether neural networks are at all suited to the much smaller data sets that are typical of natural resource management. It is yet unclear if the kind of data that are characteristic of collections of case studies (only a few hundred cases with a few hundred variables that can be aggregated to a few dozen concepts) require neural networks at all. This was one goal of this investigation.

Another important question is whether deep neural networks (with multiple hidden layers between input and output) are a suitable method to use for natural resource management. Perhaps nonmachine learning methods or very simple neural network architectures prove to be sufficient. Hence, I first introduce deep neural network architecture and shallow neural networks (only one hidden layer) before shortly characterizing other methods in order to compare their model fits on this data set, which is typical for case studies with many variables.

By now, a large variety of different architectures for neural networks exist (LeCun et al. 2015). Each type of neural network architecture is adapted to a certain kind of problem. For example, the best results on most image recognition tasks have been achieved using deep convolutional neural networks, whereas Long Short-Term Memory networks have proven to be superior to other architectures on time series analysis tasks (Hochreiter and Schmidhuber 1997). However, in principle, finding the right architecture is a matter of trial and error, especially parameter fine-tuning.

For tabular data, like those used in this article, shallow or simple deep neural networks with only a few layers have achieved good fits (Frey and Rusch 2013). Since other architectures are for other kinds of tasks, mostly highly specific, I have not further tested such architectures and have constrained my tests to feed-forward and deep feed-forward nets.

Fine-tuning such networks involves mainly adapting their hyperparameters. These are the "nuts and bolts" of a network. It is well-known that parameters like number of layers, number of hidden neurons, learning rate, or number of training epochs make a considerable difference for the final goodness-of-fit of a model
(LeCun et al. 2015). In fact, besides feature construction or extraction (providing meaningful input data; e.g., by aggregating variables), hyperparameter tuning is one of the core steps of a typical machine learning pipeline.

Again, finding the best combination of parameters is a matter of trial and error. Traditionally, researchers manually tried out the most promising combinations. However, with increasing computing power and ever more complex models, this task has been outsourced to computers. This is called grid search.

There are three types of grid search: first, Cartesian grid search, where a discrete number of parameter choices (e.g., 10, 20, and 30 number of neurons, and 50,100, and 150 epochs, which results in nine combinations) is calculated. The second type is random grid search, where values of parameters are drawn randomly from a range (e.g., number of neurons between 10 and 30; epochs between 50 and 150). Hence, the number of combinations is not fixed. Typically, the maximum number of models to be calculated is provided as a variable by the user. Third, Bayesian search, where resulting fits of parameter combinations are themselves optimized toward a decreasing error rate. This is not standard and has not yet implemented in most leading software packages (e.g., in Scikit-learn or SciPy in Python [Virtanen et al. 2019] or h2o [LeDell et al. 2020]).

It has been shown that random grid search usually yields better results than Cartesian search, which in turn performs better than manual tuning of parameters (Bergstra and Bengio 2012). Hence, I implemented a random grid search for a large parameter sweep. Since both methods are implemented very similarly in most software packages, changing it often means just changing one parameter. In h2o, for example, the parameter "strategy" of a grid search must simply be switched from "Cartesian" to "RandomDiscrete".

This systematic variation of more than 20,000 models tested (5000 runs $\mathrm{x}$ four methods) is necessary for three reasons: "

1. to be sure about the best kind of architecture, in general, for such data sets"

2. to provide very sound starting values for further parameter tuning by other researchers when modeling similar data sets

3. to make the state-of-the-art goodness-of-fit for such kinds of models known; this makes it possible to use as a benchmark and a comparison to traditional models

For all models, Table A3 presents an overview of the hyperparameters varied and the actual values of the best model. While more parameters have been tuned, those presented in Table A3 are the most important ones. Thus, for most modelers, it might be sufficient to tune only those - the rest most probably result in only very minor improvements of model quality $(<1-2 \%)$.

While my main goal was to explore the untapped possibilities of neural networks for natural resource case study data, it could be that other machine learning algorithms might perform even better. For this reason, I provide a short comparison with another algorithm - gradient boosting, a high-performing variant of decision trees (Breiman 2001a), which are perhaps the most widely used machine learning algorithms, since they have a good 
performance across a wide range of problems and are very robust against noise (Alpaydin 2010). In fact, in the natural resource management literature, as presented in the literature review in the State of research section, variants of decision trees are the most frequently used algorithm. Furthermore, their results are easily interpretable and feature importance is readily accessible.

In addition, since most case studies use regressions, I also compared the results with generalized linear models so as to be better estimate the performance boost that could be gained if neural networks are employed in natural resource research. By using a Gaussian distribution, the generalized linear models are identical to multivariate linear regressions, hence, are comparable to existing research. A description of parameters varied during grid search for model optimization are provided in Table A3.

All data were partitioned into two parts - a training (80\%) and a test set $(20 \%)$. This is standard practice in machine learning and is done to avoid overfitting. Overfitting means that a model may perform very well on the training data but is very weak on the new data (the test set) since it does not generalize very well; i.e., it captured too many details present in only the training set but not in the test set.

In addition, a five-fold cross-validation was performed. This means that a different $20 \%$ was held out for each of the five models while the training was done on $100 \%$ of the data, which was important for such a limited number of cases. Thus, metrics like goodness-of-fit are available for the training, the cross-validation, and the test sets.

I report the metrics of the test sets, which are standard, since they best explain how well the model performed on data it has not encountered before. Fig. 1 explains the workflow used.

Fig. 1. Workflow and relationship between training, validation, and test set.

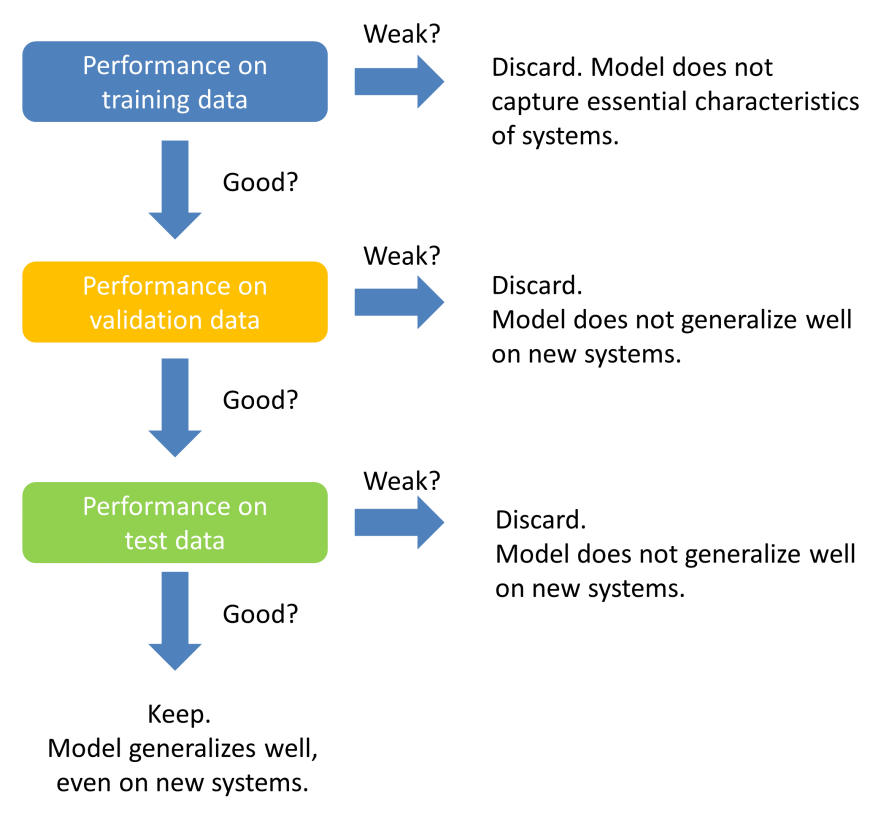

Since one of my goals was to make machine learning more widespread in the community of natural resource management and social-ecological systems, the choice of software was deliberate. I chose h2o, which is open source software (LeDell et al. 2020) and available for several programming languages; i.e., $\mathrm{R}$, Python, and Scala with very similar structure and functions. Hence, adapting the $\mathrm{R}$ code in Appendix 1 for any of the major programming languages should be very easy - in fact, a matter of hours at most. It is a standard workflow familiar to any data scientist or machine learning researcher, so further developments should be very easy.

\section{RESULTS}

For each method, a random grid search was run for 5000 (500 batches at a time) iterations. Parameters were deliberately of a wide range so as to avoid missing good model parameter combinations ("casting a wide net"). Thus, each run represented a unique combination of parameters. The best 100 models/results for each method were selected (Fig. 2). Each combination of hyperparameters was considered one model.

Fig. 2. Model quality of the best 100 models for four methods (CPR: common-pool resources; DNN: deep neural network; GBM: gradient boosting machine; GLM: generalized linear model; SNN: shallow neural network).

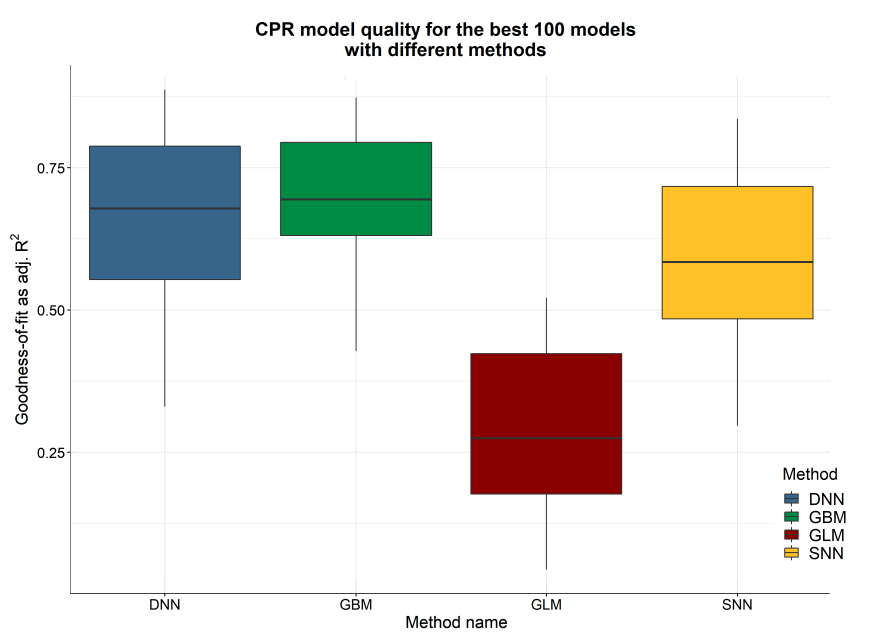

A first result is that model quality, in general, was very high. No median of machine learning models was less than 0.58 , and the multivariate regressions were at a median of 0.27 (explanation of variance). The best generalized linear model has a goodness-offit of 0.52. As is known from other fields of research, machine learning algorithms are usually very close together in terms of explanatory value. This is true for the top-performing models of my data set with deep neural networks $(0.89)$, gradient boosting machines (0.87), and shallow neural networks (0.84). However, there was a larger gap between the model quality of the regressions and the machine learning algorithms of about 0.32 (Table 1).

A second result is that deep neural networks were a bit better than shallow ones. The more complicated architecture with more hidden layers seems to have been responsible for finding even more 
Table 1. Performance comparison of machine learning algorithms on the common-pool resources data set

\begin{tabular}{lcccc}
\hline \hline $\begin{array}{l}\text { Performance/machine } \\
\text { learning algorithm }\end{array}$ & Deep neural network & $\begin{array}{c}\text { Shallow neural } \\
\text { network }\end{array}$ & $\begin{array}{c}\text { Gradient boosting } \\
\text { machine }\end{array}$ & $\begin{array}{c}\text { Linear regression } \\
\text { generalized linear } \\
\text { model) }\end{array}$ \\
\hline Min. test $R^{2}$ & 0.33 & 0.30 & 0.43 & 0.04 \\
Max. test $R^{2}$ & 0.89 & 0.84 & 0.87 & 0.52 \\
Median test $R^{2}$ & 0.68 & 0.58 & 0.69 & 0.27 \\
Mean test MSE & 0.015 & 0.020 & 0.015 & 0.035 \\
Min. train $R^{2}$ & 0.92 & 0.85 & 0.98 & 0.28 \\
Max. train $R^{2}$ & 0.99 & 0.99 & 0.99 & 0.66 \\
Median train $R^{2}$ & 0.99 & 0.96 & 0.99 & 0.49 \\
Mean train MSE & 0.0005 & 0.0020 & 0.0005 & 0.0250 \\
\hline
\end{tabular}

general patterns in the data. As can be expected with such a small data set, there was some overfitting. However, the algorithms still generalized well on the test sets.

A third result concerns the optimal architecture (Table A3). The best deep neural network had four layers with 492, 13, 85, and 111 neurons, trains for approximately 400 epochs, and has a very high learning rate of 0.12 . The number of layers and neurons determines the complexity of the problem the network is able to learn - the more layers and neurons, the more complex. However, there is a trade-off between more layers and neurons and better performance, since training time and computer resources also increase. More problematic than this, however, is that with increasing computing power of the network, overfitting occurs and generalizing abilities decrease. Finally, the learning rate defines the step size with respect to the change of weights. A higher rate means faster progress but may result in nonoptimal weights; a slower rate may result in a long training process and may get stuck in local optima.

Sometimes, combining the best, say for example five models, results in an even better predicting model. This technique of combining is called stacked ensemble. For each kind of machine learning algorithm, I calculated a stacked ensemble, altogether 40 models. However, their predictive power was not higher than the best-performing model. Thus, I do not report these results in further detail.

Hence, the results are clear-cut: "

1. All machine learning algorithms improved model quality in comparison to linear regressions."

2. The boost in model performance ranged from 35 to $40 \%$."

3. Deep neural networks (2-4 layers) increased model quality in comparison to shallow neural networks (one hidden layer only). The adjusted $R^{2}$ for this particular data set increased the goodness-of-fit by about $5 \%$."

4. Gradient boosting machines are similar in performance to deep neural networks."

5. Stacked ensembles that combine multiple models did not perform better than the best model for these kinds of tabular data."

6. Model performance varied widely. A large parameter sweep (grid search) was necessary to identify good parameter combinations.

\section{DISCUSSION}

This comparative analysis has shown that machine learning methods, in general, and deep neural networks, in particular, may offer significant advantages for the analysis of larger collections of natural resource case studies. However, one limitation of this study is that it is unclear how well one can generalize from this particular data set to other data sets. A limitation of neural networks has been their black box character; yet, with modern algorithms, the influence of independent variables is no longer unknown. They are well capable of estimating each factor independently.

Machine learning methods offer not only substantial model improvements but also decision-making support-e.g., by visualizing the importance of variables in gradient boosting, and thus may help improve ecological sustainability. Their high performance is not surprising given their ability to deal with noisy data and nonlinearities. With various software solutions being available (e.g., Keras in Python or h2o [LeDell et al. 2020]), which no longer require deeper mathematical knowledge about the functioning of neural networks, implementing machine learning algorithms should pose no issues. Nevertheless, a good understanding of the problem and the respective methods that can be applied is necessary; otherwise, the interpretation of results leads to errors. This also applies to the choice of the architecture and the method itself, even if advanced commercial software packages like keras-automl or h2o-automl offer automated workflows.

However, despite these clear advantages, machine learning methods are very rarely applied in natural resource research. I identify three main reasons why:

First, machine learning methods require large amounts of data. Therefore, individual case studies cannot be analyzed; instead, a data collection such as that available in a database is needed. In addition, these data must be fairly complete, since neural networks require complete data as input. Imputation usually leads to poor results. However, most studies deal in detail with one or fewer case studies. The lower limit for neural networks, however, is approximately 100 cases, as the demonstrated in the State of research section. Since deep neural networks can play out their advantages mostly for large data sets (e.g., images, text corpora), this may be one reason for the slow use of these techniques.

Second, data - case studies - need to be in a standardized format to be comparable (Frey 2017). Comparable, consistently 
operationalized data sets with unambiguous definitions, concepts, and variables are rare. There is a clear lack of such large, high-quality data sets in natural resource management research (Poteete et al. 2010). Open access data are still rare.

Third, unfamiliarity with machine learning methods and the approach in general (Breiman 2001b) might lead to hesitation among researchers. Until recently, it was not evident to researchers in natural resource management that machine learning could be of help in modeling. With improved and streamlined software packages available and the success stories from other fields getting more attention, this may change.

If these obstacles are overcome, an increasing spread in methods of machine learning in the field of natural resource management may also lead to a shift in research interest from individual case studies to larger data sets. This development has already been called for (Poteete et al. 2010). This in turn may lead to a different type of data collection and may change the field if data are uniformly collected, structured on the basis of a framework, mainly longitudinal, and extend across several aspects (e.g., social, economic, technical). An example of this is the International Forestry Resources and Institutions database, which has enabled many scientific findings to be achieved (e.g., Andersson and Agrawal 2011, Salk et al. 2014).

Support could also come from increasing performance of computers, which could speed up computations of complex models considerably. Just to name a few possibilities: computing on graphics processing units, using parallel computing software like MPI (message passing interface) on local laptops, or using server clusters in the researcher's scientific institution. If even more computational power is required, high-performance or cloud computing are readily available.

\section{CONCLUSION}

The successes of machine learning in many fields of research suggest that their modeling qualities can also be used for analyses in the field of natural resource management. However, this has hardly happened so far - a literature review resulted in only 32 reviewed papers in both more general and topic-specific journals at the interface of machine learning and natural resource management.

I have identified a number of potential reasons why machine learning is rarely applied in natural resource research and have suggested how obstacles in applying machine learning could be overcome. It is not due to the unavailability of suitable data sets, as collections of case studies in meta-analyses (Gutiérrez et al. 2011, Brooks et al. 2012) and research using databases (Tang 1992, Lam 1998, Salk et al. 2014) have proven. I also established that machine learning algorithms are probably well suited to deal with the kind of data that exist in natural resource management.

All algorithms tested (deep and shallow neural networks, and gradient boosting) had a superior explanatory power over traditional linear regressions. However, no algorithm emerged as clearly superior to the others - results were also dependent on the data set and its features. It is important to stress again that models vary widely depending on parameter tuning. In order to identify robust patterns, it is necessary to both run many models and use multiple machine learning algorithms. Only if a pattern is stable across many models and at least two algorithms is there an indication for its existence.
Future research could be based on well-tested architectures. Since all analyses were performed on open access data with open source tools, one such workflow is presented in this article, with the full code provided in Appendix 1. Therefore, adapting such models to one's own data set may consist only of fine-tuning some parameters. For example, this is common practice in image recognition. Furthermore, standard data formats, common definitions of central concepts, and reference data sets and benchmarks for comparing different methods are future central building blocks for advancing natural resource management research.

This brings us to the conclusion that the many different methods of machine learning, not only neural networks, could enrich the methodological toolbox of social-ecological systems analysis. Machine learning methods have proven their worth in many fields, they are both theoretically and practically mature, and there are many easy-to-use software solutions and corresponding introductions and instructions (e.g., the h2o [http://docs.h2o.ai/] or Keras documentation [https://keras.io/]). It is therefore time to apply these methods to questions of natural resource management.

\section{Responses to this article can be read online at: https://www.ecologyandsociety.org/issues/responses. $\mathrm{php} / 12124$}

\section{Data Availability:}

The data are publicly available on the internet (https://seslibrary. asu.edulcpr).

\section{LITERATURE CITED}

Alpaydin, E. 2010. Introduction to machine learning. Second edition. MIT Press, Cambridge, Massachusetts, USA.

Álvarez-Romero, J. G., R. L. Pressey, N. C. Ban, and J. Brodie. 2015. Advancing land-sea conservation planning: integrating modelling of catchments, land-use change, and river plumes to prioritise catchment management and protection. PLOS ONE 10 (12):e0145574. https://doi.org/10.1371/journal.pone.0145574

Andersson, K., and A. Agrawal. 2011. Inequalities, institutions, and forest commons. Global Environmental Change 21(3):866-875. https://doi.org/10.1016/j.gloenvcha.2011.03.004

Bergstra, J., and Y. Bengio. 2012. Random search for hyperparameter optimization. Journal of Machine Learning Research 13:281-305.

Breiman, L. 2001a. Random forests. Machine Learning 45 (1):5-32. https://doi.org/10.1023/A:1010933404324

Breiman, L. 2001b. Statistical modeling: the two cultures (with comments and a rejoinder by the author). Statistical Science 16 (3):199-231. https://doi.org/10.1214/ss/1009213726

Brooks, J. S., K. A. Waylen, and M. Borgerhoff Mulder. 2012. How national context, project design, and local community characteristics influence success in community-based conservation projects. Proceedings of the National Academy of Sciences of the 
United States of America 109(52):21265-21270. https://doi. org/10.1073/pnas. 1207141110

Brown, N., and T. Sandholm. 2019. Superhuman AI for multiplayer poker. Science 365(6456):885-890. https://doi. org/10.1126/science.aay 2400

Cao, C., S. Dragićević, and S. Li. 2019. Short-term forecasting of land use change using recurrent neural network models. Sustainability 11(19):5376. https://doi.org/10.3390/su11195376

Cenek, M., and M. Franklin. 2017. An adaptable agent-based model for guiding multi-species Pacific salmon fisheries management within a SES framework. Ecological Modelling 360:132-149. https://doi.org/10.1016/i.ecolmodel.2017.06.024

Ching, T., D. S. Himmelstein, B. K. Beaulieu-Jones, A. A. Kalinin, B. T. Do, G. P. Way, E. Ferrero, P.-M. Agapow, M. Zietz, M. M. Hoffman, et al. 2018. Opportunities and obstacles for deep learning in biology and medicine. Journal of the Royal Society, Interface 15(141). https://doi.org/10.1098/rsif.2017.0387

Crespo, G. O., D. C. Dunn, G. Reygondeau, K. Boerder, B. Worm, W. Cheung, D. P. Tittensor, and P. N. Halpin. 2018. The environmental niche of the global high seas pelagic longline fleet. Science Advances 4(8):eaat3681. https://doi.org/10.1126/sciadv. aat3681

Elith, J., C. H. Graham, R. P. Anderson, M. Dudík, S. Ferrier, A. Guisan, R. J. Hijmans, F. Huettmann, J. R. Leathwick, A. Lehmann, et al. 2006. Novel methods improve prediction of species' distributions from occurrence data. Ecography 29 (2):129-151. https://doi.org/10.1111/j.2006.0906-7590.04596.x

Fernández-Delgado, M., E. Cernadas, S. Barro, and D. Amorim. 2014. Do we need hundreds of classifiers to solve real world classification problems? Journal of Machine Learning Research 15(1):3133-3181.

Frey, U. 2018. Nachhaltige Bewirtschaftung natürlicher Ressourcen: Erfolgsfaktoren in komplexen sozial-ökologischen Systemen. [1. Auflage] edition. Springer Spektrum, Berlin, Germany. https://doi.org/10.1007/978-3-662-55446-3

Frey, U. J. 2017. A synthesis of key factors for sustainability in social-ecological systems. Sustainability Science 12(4):507-519. https://doi.org/10.1007/s11625-016-0395-z

Frey, U. J., and H. Rusch. 2013. Using artificial neural networks for the analysis of social-ecological systems. Ecology and Society 18(2):40. https://doi.org/10.5751/ES-05202-180240

Frey, U. J., and H. Rusch. 2014. Modelling ecological success of common pool resource systems using large datasets. World Development 59:93-103. https://doi.org/10.1016/j.worlddev.2014.01.034

Girshick, R. 2015. Fast R-CNN. [online] URL: http://arxiv.org/ pdf/1504.08083v2

Gutiérrez, N. L., R. Hilborn, and O. Defeo. 2011. Leadership, social capital and incentives promote successful fisheries. Nature 470(7334):386-389. https://doi.org/10.1038/nature09689

Hochreiter, S., and J. Schmidhuber. 1997. Long short-term memory. Neural Computation 9(8):1735-1780. https://doi. org/10.1162/neco.1997.9.8.1735
Humphries, G., D. R. Magness, and F. Huettmann, editors. 2018. Machine learning for ecology and sustainable natural resource management. Springer International Publishing. https://doi. org/10.1007/978-3-319-96978-7

Intergovernmental Panel on Climate Change (IPCC). 2018. Global warming of $1.5^{\circ} \mathrm{C}$. Special report. [online] URL: https:// www.ipcc.ch/sr15/

Johnson, M., M. Schuster, Q. V. Le, M. Krikun, Y. Wu, Z. Chen, N. Thorat, F. Viégas, M. Wattenberg, G. Corrado, M. Hughes, and J. Dean. 2017. Google's multilingualneural machine translation system: enabling zero-shot translation. https://doi.org/10.1162/ tacl a 00065

Jules Dreyfus-León, M. 1999. Individual-based modelling of fishermen search behaviour with neural networks and reinforcement learning. Ecological Modelling 120(2-3):287-297. https://doi.org/10.1016/S0304-3800(99)00109-X

Lam, W. F. 1998. Governing irrigation systems in Nepal: institutions, infrastructure, and collective action. Institute for Contemporary Studies, San Francisco.

Le, Q. V., M.'A. Ranzato, R. Monga, M. Devin, K. Chen, G. S. Corrado, J. Dean, and A. Y. Ng. 2012. Building high-level features using large scale unsupervised learning. Pages 507-514 in Proceedings of the 29th International Conference on Machine Learning, Edinburgh, Scotland, UK, 2012. [online] URL: http:// arxiv.org/pdf/1112.6209v5

LeCun, Y., Y. Bengio, and G. Hinton. 2015. Deep learning. Nature 521(7553):436-444. https://doi.org/10.1038/nature14539

LeDell, E., N. Gill, S. Aiello, A. Fu, A. Candel, C. Click, T. Kraljevic, T. Nykodym, P. Aboyoun, M. Kurka, et al. 2020. h2o: $\mathrm{R}$ interface for the 'H2O' scalable machine learning platform. [online] URL: https://rdrr.io/cran/h2o/

Magierowski, R. H., S. M. Read, S. J. B. Carter, D. M. Warfe, L. S. Cook, E. C. Lefroy, and P. E. Davies. 2015. Inferring landscapescale land-use impacts on rivers using data from mesocosm experiments and artificial neural networks. PLOS ONE 10(3): e0120901. https://doi.org/10.1371/journal.pone.0120901

Mnih, V., K. Kavukcuoglu, D. Silver, A. A. Rusu, J. Veness, M. G. Bellemare, A. Graves, M. Riedmiller, A. K. Fidjeland, G. Ostrovski, et al. 2015. Human-level control through deep reinforcement learning. Nature 518(7540):529-533. https://doi. org/10.1038/nature 14236

O'Farrell, S., J. N. Sanchirico, O. Spiegel, M. Depalle, A. C. Haynie, S. A. Murawski, L. Perruso, and A. Strelcheck. 2019. Disturbance modifies payoffs in the explore-exploit trade-off. Nature Communications 10(1):3363. https://doi.org/10.1038/ s41467-019-11106-y

Ostrom, E. 1990. Governing the commons: the evolution of institutions for collective action. Cambridge University Press, Cambridge.

Paruelo, J., and F. Tomasel. 1997. Prediction of functional characteristics of ecosystems: a comparison of artificial neural networks and regression models. Ecological Modelling 98 (2-3):173-186. https://doi.org/10.1016/S0304-3800(96)01913-8 
Poteete, A. R., M. A. Janssen, and E. Ostrom. 2010. Working together: collective action, the commons, and multiple methods in practice. Princeton University Press, Princeton, New Jersey, USA. https://doi.org/10.1515/9781400835157

Salk, C. F., U. Frey, and H. Rusch. 2014. Comparing forests across climates and biomes: qualitative assessments, reference forests and regional intercomparisons. PLoS ONE 9(4):e94800. https:// doi.org/10.1371/journal.pone.0094800

Saputra, M. H., and H. S. Lee. 2019. Prediction of land use and land cover changes for North Sumatra, Indonesia, using an artificial-neural-network-based cellular automaton. Sustainability 11(11):3024. https://doi.org/10.3390/su11113024

Silver, D., J. Schrittwieser, K. Simonyan, I. Antonoglou, A. Huang, A. Guez, T. Hubert, L. Baker, M. Lai, A. Bolton, et al. 2017. Mastering the game of Go without human knowledge. Nature 550(7676):354-359. https://doi.org/10.1038/nature24270

Tang, S. Y. 1992. Institutions and collective actions: self-governance in irrigation. Institute for Contemporary Studies, San Francisco, California, USA.

Václavik, T., S. Lautenbach, T. Kuemmerle, and R. Seppelt. 2013. Mapping global land system archetypes. Global Environmental Change 23(6):1637-1647. https://doi.org/10.1016/j.gloenvcha.2013.09.004

Virtanen, P., R. Gommers, T. E. Oliphant, M. Haberland, T. Reddy, D. Cournapeau, E. Burovski, P. Peterson, W. Weckesser, J. Bright, et al. 2019. SciPy 1.0 - fundamental algorithms for scientific computing in Python. [online] URL: http://arxiv.org/ pdf/1907.10121v1 


\section{Appendix 1. Supporting online material}

\section{Results of literature search}

Table A1. Hits found in the systematic literature search

\begin{tabular}{|c|c|c|c|c|c|}
\hline Journal name & $\begin{array}{l}\text { Number of } \\
\text { hits for } \\
\text { search } \\
\text { term: } \\
\text { machine } \\
\text { learning } \\
\text { (ML) }\end{array}$ & $\begin{array}{c}\text { Number of } \\
\text { hits for } \\
\text { search term: } \\
\text { deep learning }\end{array}$ & $\begin{array}{c}\text { Number of } \\
\text { hits for } \\
\text { search term: } \\
\text { neural } \\
\text { network }\end{array}$ & $\begin{array}{l}\text { Sum of hits } \\
\text { for all search } \\
\text { terms }\end{array}$ & $\begin{array}{c}\text { Actual hits } \\
\text { after } \\
\text { screening; } \\
\text { i.e., using } \\
\text { ML for } \\
\text { natural } \\
\text { resource } \\
\text { management }\end{array}$ \\
\hline $\begin{array}{l}\text { Ecology \& } \\
\text { Society }\end{array}$ & 0 & 12 & 1 & 13 & 1 \\
\hline $\begin{array}{l}\text { International } \\
\text { Journal of the } \\
\text { Commons }\end{array}$ & 8 & 16 & 18 & 42 & 0 \\
\hline Sustainability & 80 & 28 & 137 & 245 & 8 \\
\hline $\begin{array}{l}\text { Ecological } \\
\text { Modeling }\end{array}$ & 219 & 3 & 541 & 763 & 2 \\
\hline $\begin{array}{l}\text { Global } \\
\text { Environmental } \\
\text { Change }\end{array}$ & 13 & 4 & 14 & 31 & 1 \\
\hline $\begin{array}{l}\text { World } \\
\text { Development }\end{array}$ & 10 & 3 & 7 & 20 & 1 \\
\hline $\begin{array}{l}\text { Journal of } \\
\text { Environmental } \\
\text { Management }\end{array}$ & 103 & 2 & 219 & 324 & 0 \\
\hline $\begin{array}{l}\text { Journal of } \\
\text { Cleaner } \\
\text { Production }\end{array}$ & 199 & 75 & 580 & 854 & 0 \\
\hline $\begin{array}{l}\text { Environmental } \\
\text { Modeling and } \\
\text { Software }\end{array}$ & 311 & 35 & 500 & 846 & 4 \\
\hline
\end{tabular}




\begin{tabular}{|c|c|c|c|c|}
\hline PLoS ONE & $38+201$ & $66+9$ & $653+144$ & $757+354$ \\
\hline $\begin{array}{l}\text { Proceedings of } \\
\text { the National } \\
\text { Academy of } \\
\text { Science } \\
\text { (PNAS) }\end{array}$ & $137+438$ & $51+209$ & $188+205$ & $376+852$ \\
\hline $\begin{array}{l}\text { Proceedings of } \\
\text { the Royal } \\
\text { Society B }\end{array}$ & $59+71$ & $11+25$ & $52+117$ & $122+213$ \\
\hline Nature & $13+57$ & $3+21$ & $6+58$ & $22+136$ \\
\hline Science & $38+88$ & $1+22$ & $18+34$ & $57+144$ \\
\hline $\begin{array}{l}\text { Nature } \\
\text { Methods }\end{array}$ & $2+26$ & $0+24$ & $2+27$ & $4+77$ \\
\hline $\begin{array}{l}\text { Nature } \\
\text { Climate } \\
\text { Change }\end{array}$ & $4+17$ & $25+44$ & $1+5$ & $30+66$ \\
\hline $\begin{array}{l}\text { Nature } \\
\text { Sustainability }\end{array}$ & $5+13$ & $20+32$ & $0+4$ & $25+49$ \\
\hline
\end{tabular}

Note: The first number in a cell indicates the hits for "social ecological"; the second number indicates "natural resource". 


\section{Overview of all articles using machine learning methods}

Table A2. Overview of all articles using machine learning (ML) methods on a topic in natural resource management

$\mathrm{NN}=$ artificial neural network; $\mathrm{RF}=$ random forest $\mathrm{SVM}=$ support vector machine; $\mathrm{RFL}=$ reinforcement learning; $\mathrm{ABM}=$ agent-based modeling; $\mathrm{BRT}=$ boosted regression trees; $\mathrm{MRT}$ $=$ multivariate regression trees

\begin{tabular}{|c|c|c|c|c|c|}
\hline Authors & Year & DOI & Topic & $\begin{array}{l}\text { Type of } \\
\text { ML } \\
\text { used }\end{array}$ & Journal \\
\hline $\begin{array}{l}\text { Adisa et } \\
\text { al. }\end{array}$ & 2019 & https://doi.org/10.3390/su11041145 & $\begin{array}{l}\text { Predict } \\
\text { Maize } \\
\text { Production } \\
\text { in South } \\
\text { Africa }\end{array}$ & $\mathrm{NN}$ & $\begin{array}{l}\text { Sustaina- } \\
\text { bility }\end{array}$ \\
\hline $\begin{array}{l}\text { Alvarez- } \\
\text { Romero et } \\
\text { al. }\end{array}$ & 2015 & $\begin{array}{l}\text { https://doi.org/10.1371/journal.pone. } \\
0145574\end{array}$ & $\begin{array}{l}\text { Estimate } \\
\text { Probability } \\
\text { of land use } \\
\text { change and } \\
\text { river } \\
\text { plumes }\end{array}$ & $\mathrm{NN}$ & PLoS ONE \\
\hline Arima & 2016 & $\begin{array}{l}\text { https://doi.org/10.1371/journal.pone. } \\
0152058\end{array}$ & $\begin{array}{l}\text { Simulate } \\
\text { impact of } \\
\text { road } \\
\text { constructio } \\
\mathrm{n} \text { on } \\
\text { deforestatio } \\
\mathrm{n} \text { and } \\
\text { quantify } \\
\text { carbon } \\
\text { emissions }\end{array}$ & $\begin{array}{l}\text { Bayesian } \\
\text { probit } \\
\text { land } \\
\text { change } \\
\text { model }\end{array}$ & PLoS ONE \\
\hline Cao et al. & 2019 & https://doi.org/10.3390/su11195376 & $\begin{array}{l}\text { Short-Term } \\
\text { Forecast of } \\
\text { Land Use } \\
\text { Change }\end{array}$ & $\begin{array}{l}\text { NN } \\
\text { (Recurre } \\
\text { nt) }\end{array}$ & $\begin{array}{l}\text { Sustaina- } \\
\text { bility }\end{array}$ \\
\hline $\begin{array}{l}\text { Cenek et } \\
\text { al. }\end{array}$ & 2017 & $\begin{array}{l}\text { https://doi.org/10.1016/j.ecolmodel.2 } \\
\text { 017.06.024 }\end{array}$ & $\begin{array}{l}\text { Machine } \\
\text { learning } \\
\text { evolved } \\
\text { agent } \\
\text { behaviors } \\
\text { for }\end{array}$ & $\mathrm{ABM}$ & $\begin{array}{l}\text { Ecological } \\
\text { modelling }\end{array}$ \\
\hline
\end{tabular}


fishermen

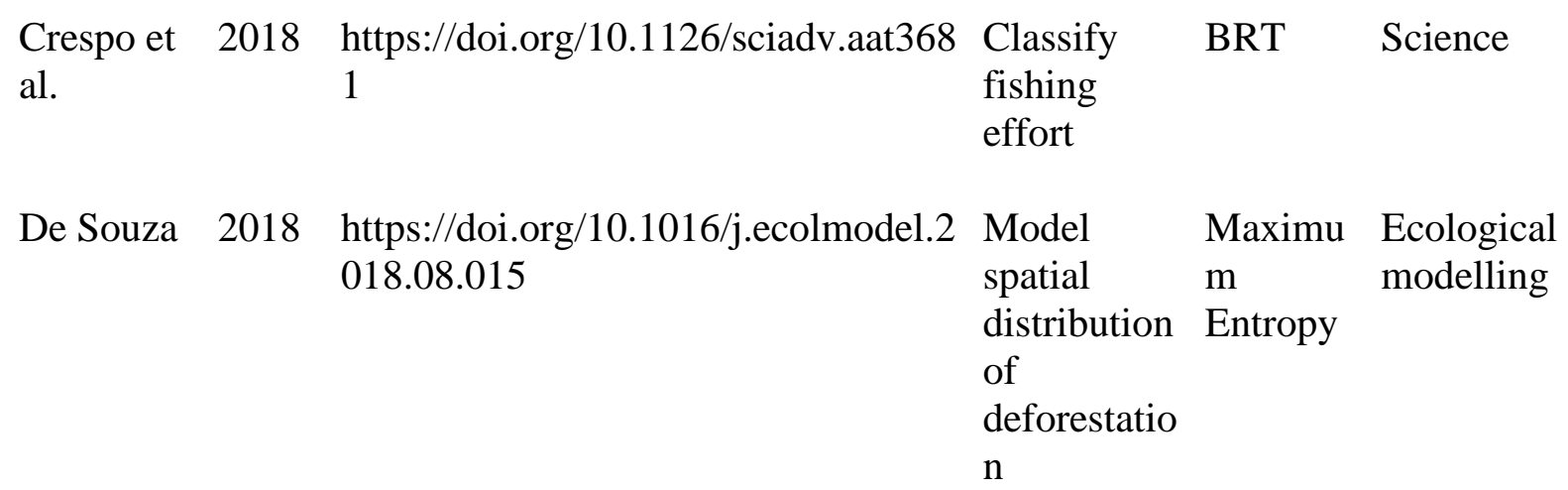

$\begin{array}{lllll}\text { Dreyfus- } 1999 \text { https://doi.org/10.1016/S0304- } & \text { Model } & \mathrm{NN}+\text { Ecological }\end{array}$

Leon et al. $\quad 3800(99) 00109-\mathrm{X}$

fishermen RFL modelling

search

behaviour

Ekasingh 2009 https://doi.org/10.1016/j.envsoft.200 Predict crop Decision Environ-

et al.

9.02.015

choice

trees mental

Modeling and Soft-

ware

Fan et al. 2018 https://doi.org/10.1371/journal.pone. Predict the SVM PLoS ONE 0198171

effectivenes

s of

farmland

consolidati

on

Farrell et 2019 https://doi.org/10.1038/s41467-019- Simulate RF Nature al. 11106-y

Exploratory strategies in fishers

Frey et al. 2014 https://doi.org/10.1016/j.worlddev.20 P 14.01.034

legal

NN World

security,

Develop-

institutional

ment

fairness and

other

factors in

irrigation

systems and

fisheries

Frey et al. 2013 https://doi.org/10.5751/ES-05202180240

$\begin{array}{lll}\text { Model } & \text { NN } & \begin{array}{l}\text { Ecology \& } \\ \text { Society }\end{array} \\ \text { fuccess } & & \end{array}$


social-

ecological

systems

Gasche et 2013 https://doi.org/10.1371/journal.pone. Predict

al. 0077566

RF

PLOS ONE

populations

of sole and

plaice to

control fish

harvesting

Gutierrez 2011 https://doi.org/10.1038/nature09689

Predict

RF Nature et al.

success

factors for

fisheries

Jouffray

2019

44

Estimate

BRT

Procee-

relative

influence of

dings of the

human and

Royal

environmen

Society B

tal variables

in shaping

reef

ecosystems

Keane et

https://doi.org/10.1038/s41893-019-

Impact of

Bayesian Nature

al.

0458-0

wildlife

manage-

Network Sustaina-

ment areas

bility

on

community

wealth

Li et al.

http://dx.doi.org/10.1016/j.envsoft.2

017.07.016

Predict

sponge

species

richness

RF,

Environ-

GLM

mental

Modeling

and Soft-

ware

Lindkvist 2017 https://doi.org/10.1098/rspb.2016.27 62

Estimate

RFL

Procee-

performanc

e of

dings of the

different

managemen

Royal

Society B

t strategies

Little et 2007 https://doi.org/10.1016/j.ecolmodel.2 Simulate

al. $\quad 007.01 .013$

agents

$\mathrm{ABM}+$ Ecological

harvesting a Network

renewable 
resource

Magierow 2015 https://doi.org/10.1371/journal.pone. Identify ski et al. 0120901

$\mathrm{NN}$

PLoS ONE

land-use

drivers of

changes in

river

condition

Maldonad 2018 https://doi.org/10.3390/su10114312 Compariso Various Sustainao et al.

$\mathrm{n}$ of ML- $\quad(\mathrm{NN}, \mathrm{RF}$, bility

methods to Bayesian

select networks

socioecono )

mic

indicators

in cultural

landscapes

Mayfield 2017 http://dx.doi.org/10.1016/j.envsoft.2 Predict Various Environet al. $\quad 016.10 .006$

deforesta- (GLM, mental

tion Bayesian Modeling

Network, and Soft-

$\mathrm{NN}, \ldots)$ ware

Nguyen et 2019 https://doi.org/10.3390/su11133615 Predict soil RF Sustainaal.

erosion

bility

Ouyang et 2019 https://doi.org/10.3390/su11226416

Identify Bayesian Sustainaal.

ecological Network bility

security Machine

patterns Learning

Robinson 2020 https://doi.org/10.1016/j.envsoft.202 et al. 0.104781

Early
warning
detection of
water
supply
vulnera-
bility

Various Environmental Modeling and Software

Romulo et 2018 https://doi.org/10.1038/s41467-018al. 06538-x

Predict
investments
in
watershed
services
(IWS)
programs

RF Nature programs 
al.

land cover bility

changes

Vaclavik 2013 https://doi.org/10.1016/j.gloenvcha.2 et al. 013.09.004

Classify NN Global land system (Self- Environarchetypes organizi mental ng map) Change

Woo et al. 2019 https://doi.org/10.3390/su11123397 Measure RF Sustainaecosystem bility health

Yates et 2016 https://doi.org/10.1371/journal.pone. Model fish BRT and PLoS ONE al. 0155634 species MRT

richness

and abundance of fish functional groups

Zhang et 2018 https://doi.org/10.3390/su10124600 al.

\begin{tabular}{|c|}
\hline $\begin{array}{l}\text { Predict } \\
\text { long-term } \\
\text { water } \\
\text { system } \\
\text { adaptation } \\
\text { planning }\end{array}$ \\
\hline
\end{tabular}




\section{Description of parameters}

Table A3. Description of parameters varied during grid-search for model-optimization for three machine learning algorithms

\begin{tabular}{|c|c|c|c|c|}
\hline Method & Parameter & Description & Range varied & Optimum \\
\hline \multirow[t]{2}{*}{$\begin{array}{l}\text { Generalized } \\
\text { linear model }\end{array}$} & Lambda & $\begin{array}{l}\text { controls amount of } \\
\text { regularization }\end{array}$ & $0-1$ & 0.4 \\
\hline & Alpha & $\begin{array}{l}\text { controls distribution } \\
\text { between } 11 \text { and } 12 \\
\text { penalties }\end{array}$ & $0-1$ & 0 \\
\hline \multirow{5}{*}{$\begin{array}{l}\text { Gradient } \\
\text { boosting }\end{array}$} & Number of trees & & $50-2.500$ & 1900 \\
\hline & Sample rate & $\begin{array}{l}\% \text { data sampled (for } \\
\text { generalization) }\end{array}$ & $0.4-1.0$ & 0.85 \\
\hline & Max. depth & deepness of tree & $5-15$ & 6 \\
\hline & $\begin{array}{l}\text { Column sample } \\
\text { rate }\end{array}$ & $\begin{array}{l}\text { Number of columns } \\
\text { sampled for each split }\end{array}$ & $0.2-0.5$ & 0.32 \\
\hline & $\begin{array}{l}\text { Column sample } \\
\text { rate per tree }\end{array}$ & $\begin{array}{l}\text { column sampling rates } \\
\text { per tree }\end{array}$ & $0.2-0.7$ & 0.44 \\
\hline \multirow[t]{3}{*}{$\begin{array}{l}\text { Shallow neural } \\
\text { networks }\end{array}$} & Epochs & $\begin{array}{l}\text { Number of cycles on } \\
\text { the training set }\end{array}$ & $30-500$ & 305 \\
\hline & Learning rate & $\begin{array}{l}\text { Step size in gradient } \\
\text { descent optimization }\end{array}$ & $0.001-0.3$ & 0.15 \\
\hline & $\begin{array}{l}\text { Number of } \\
\text { hidden neurons }\end{array}$ & $\begin{array}{l}\text { number of neurons in } \\
\text { calculating layer }\end{array}$ & $10-500$ & 391 \\
\hline \multirow{4}{*}{$\begin{array}{l}\text { Deep neural } \\
\text { networks }\end{array}$} & Epochs & as above & $30-500$ & 403 \\
\hline & Learning rate & as above & $0.001-0.3$ & 0.12 \\
\hline & $\begin{array}{l}\text { Number of } \\
\text { hidden layers }\end{array}$ & $\begin{array}{l}\text { number of calculating } \\
\text { layers }\end{array}$ & $2-4$ & 4 \\
\hline & $\begin{array}{l}\text { Number of } \\
\text { hidden neurons }\end{array}$ & as above & $10-500$ & 492-13-85-111 \\
\hline
\end{tabular}




\section{Variables in Ecological Success}

Table A4. Common-pool resouces - Description of variables ecological success consists of

\begin{tabular}{|c|c|c|}
\hline Variable name & $\begin{array}{l}\text { Type of } \\
\text { data }\end{array}$ & Short description \\
\hline loc_ENDDATE & Number & Begin and End date (end) \\
\hline opl_BEGDATE & Number & Begin and End date (beginning) \\
\hline Opl_BMARKETS & Likert scale & How are the appropriated units disposed of (beginning)? \\
\hline opl_CONDITON & Likert scale & Physical condition of the system \\
\hline opl_EAVERAGE & Number & $\begin{array}{l}\text { Average age of the units withdrawn from this resource at } \\
\text { the end }\end{array}$ \\
\hline opl_EAVERSIZ & Number & $\begin{array}{c}\text { Average size of the units withdrawn from this resource at } \\
\text { the end }\end{array}$ \\
\hline opl_ECONEFF & Likert scale & Short-run Economic Technical Efficiency \\
\hline opl_effindc & Text & Indicators and means of increasing efficiency \\
\hline Opl_EMARKETS & Likert scale & How are the appropriated units disposed of (end)? \\
\hline opl_ENDBLNC & Likert scale & $\begin{array}{l}\text { Balance between quantity of units withdrawn and number } \\
\text { available (end) }\end{array}$ \\
\hline opl_ENDCONDA & Likert scale & $\begin{array}{l}\text { How well-maintained is the appropriation resource } \\
\qquad \text { (end)? }\end{array}$ \\
\hline opl_ENDCONDD & Likert scale & How well-maintained is the distribution resource (end)? \\
\hline opl_ENDCONDP & Likert scale & How well-maintained is the production resource (end)? \\
\hline opl_ENDDATE & Number & Beginning and ending of the operational level \\
\hline opl_ENDNTFER & Likert scale & $\begin{array}{l}\text { Interference between technology and processes for other } \\
\text { resources (end) }\end{array}$ \\
\hline opl_ENDPOLL & Likert scale & Problems of pollution (end) \\
\hline opl_ENDQUAL & Likert scale & Quality of units being withdrawn (end) \\
\hline opl_ENDRATE1 & Number & Volume of withdrawal for fisheries (end) \\
\hline opl_ENDRATE3 & Number & Volume of withdrawal for irrigation (end) \\
\hline
\end{tabular}




\begin{tabular}{|c|c|c|}
\hline opl_ENDTECHX & Likert scale & Extent of technical externalities (end) \\
\hline opl_ESEXDEVL & Likert scale & Are the units sexually mature at this size or age (end)? \\
\hline opl_Evaluate & Text & $\begin{array}{c}\text { Brief synopsis of how this system is evaluated } \\
\text { (performance) }\end{array}$ \\
\hline opl_MTONHA & Number & Metric tons of agricultural product per year per hectare \\
\hline opl_NEWTECH & Likert scale & Is new technology introduced? \\
\hline opl_NEWVALUE & Likert scale & External change in exchange value of units appropriated? \\
\hline opl_ONEMARKT & Likert scale & Do appropriators sell this unit in more than one market? \\
\hline opl_TAILEND & Likert scale & Adequacy and predictability of water to tailenders \\
\hline opl_TECHEFF & Likert scale & Technical Effectiveness of water availability \\
\hline opl_TYPRESUL & Text & Evaluation of results \\
\hline res_MULTAPPR & Likert scale & Relationship among multiple appropration processes \\
\hline res_WHENBILT & Number & Date of construction of system \\
\hline sbg_LGTHUSE & Likert scale & Length of time this subgroup has regularly appropriated \\
\hline scr_paragrph & Text & Abstract of document being screened \\
\hline
\end{tabular}

\section{Variable - to - Concept Mapping for the common-pool resources data}

\begin{tabular}{|llll|}
\hline Variable Name & Mapped to concept & Variable Name & Mapped to concept \\
loc_LOCDSCPT & Resource size & ors_Membappr & Participation of users \\
loc_LOCSIZE & Resource size & ors_Orgparag & Participation of users \\
opl_endrate2 & Resource size & res_DISTHEAD & Participation of users \\
res_APPRESRC & Resource size & res_DISTOPER & Participation of users \\
res_BRANCHES & Resource size & res_DISTSAME & Participation of users \\
res_LENGTH & Resource size & res_HEADOPER & Participation of users \\
res_LNTHBRCH & Resource size & res_HEADSAME & Participation of users \\
res_LNTHMAIN & Resource size & res_SECTOR2 & Participation of users
\end{tabular}




\begin{tabular}{|c|c|c|c|c|c|c|}
\hline res_METHEAD1 & Resource size & \multicolumn{2}{|c|}{ res_SELEDIST } & \multicolumn{3}{|c|}{ Participation of users } \\
\hline res_METHEAD2 & Resource size & \multicolumn{2}{|c|}{ res_SELPROD } & \multicolumn{3}{|c|}{ Participation of users } \\
\hline res_STOREVOL & Resource size & \multicolumn{2}{|c|}{ sbg_MANAGE } & \multicolumn{3}{|c|}{ Participation of users } \\
\hline res_SURFAREA & Resource size & \multicolumn{2}{|c|}{ sbg_PROnurul } & \multicolumn{3}{|c|}{ Participation of users } \\
\hline res_SYSTAREA & Resource size & \multicolumn{2}{|c|}{ scr_TYPE } & \multicolumn{3}{|c|}{ Participation of users } \\
\hline scr_Slocsize & Resource size & \multicolumn{5}{|c|}{ sbg_WITHDRAW Legal certainty and legitimacy } \\
\hline loc_LOCBOUND & \multicolumn{2}{|c|}{ Resource boundaries } & \multicolumn{2}{|c|}{ loc_ENDDATE } & \multicolumn{2}{|c|}{ Legal certainty and legitimacy } \\
\hline loc_LOCDSCPT & \multicolumn{4}{|c|}{ Resource boundaries } & \multicolumn{2}{|c|}{ Legal certainty and legitimacy } \\
\hline opl_RECORDav & \multicolumn{2}{|c|}{ Resource boundaries } & \multicolumn{2}{|c|}{ loc_jurinam1 } & \multicolumn{2}{|c|}{ Legal certainty and legitimacy } \\
\hline opl_RECORDwi & \multicolumn{2}{|c|}{ Resource boundaries } & \multicolumn{2}{|c|}{ loc_jurinam2 } & \multicolumn{2}{|c|}{ Legal certainty and legitimacy } \\
\hline opl_USERseen & \multicolumn{2}{|c|}{ Resource boundaries } & \multicolumn{2}{|c|}{ loc_locjuris } & \multicolumn{2}{|c|}{ Legal certainty and legitimacy } \\
\hline res_BOUNDAR2 & \multicolumn{2}{|c|}{ Resource boundaries } & \multicolumn{2}{|c|}{ IOC_ONECOUNT } & \multicolumn{2}{|c|}{ Legal certainty and legitimacy } \\
\hline res_BOUNDAR3 & \multicolumn{2}{|c|}{ Resource boundaries } & \multicolumn{2}{|c|}{ Opl_BFORMOWN } & \multicolumn{2}{|c|}{ Legal certainty and legitimacy } \\
\hline res_BOUNDAR4 & \multicolumn{2}{|c|}{ Resource boundaries } & opl_E & IBERY & Legal certainty & and legitimacy \\
\hline res_DESCRIPT & Resource bou & aries & opl_c & ration & Legal certainty & and legitimacy \\
\hline res_DISTAPPR & Resource bou & aries & opl_E & ddate & Legal certainty & and legitimacy \\
\hline res_OFFNUM & Resource bou & aries & opr_t & Fpay & Legal certainty & and legitimacy \\
\hline res_PRODAPPR & Resource boul & aries & opr_r & tcolch & Legal certainty & and legitimacy \\
\hline res_PRODDIST & Resource boul & aries & opr_r & gcolch & Legal certainty & and legitimacy \\
\hline res_PRODLOCA & Resource bou & aries & opr2 & EGITIM & Legal certainty & and legitimacy \\
\hline loc_LOCDSCPT & Accessibility & ors_ & gdate & Legal ce & rtainty and legit & macy \\
\hline opr2_seasonln & Accessibility & ors_ & nelect & Legal ce & rtainty and legit & macy \\
\hline res_AVGACCES & Accessibility & ors_ & ddate & Legal ce & rtainty and legit & macy \\
\hline res_STEEP & Accessibility & ors_ & pother & Legal ce & rtainty and legit & macy \\
\hline sbg_RESIDENT & Accessibility & ors_ & pown & Legal ce & rtainty and legit & macy \\
\hline loc_BEGDATE & Ecological suc & $\mathrm{s}$ at $\mathrm{t}$ & beginn & & ors_Extremov & Legal certainty and legitimacy \\
\hline opl_BAVERSIZ & Ecological suc & s at $t$ & beginn & & ors Extrep & Legal certainty and legitimacy \\
\hline
\end{tabular}




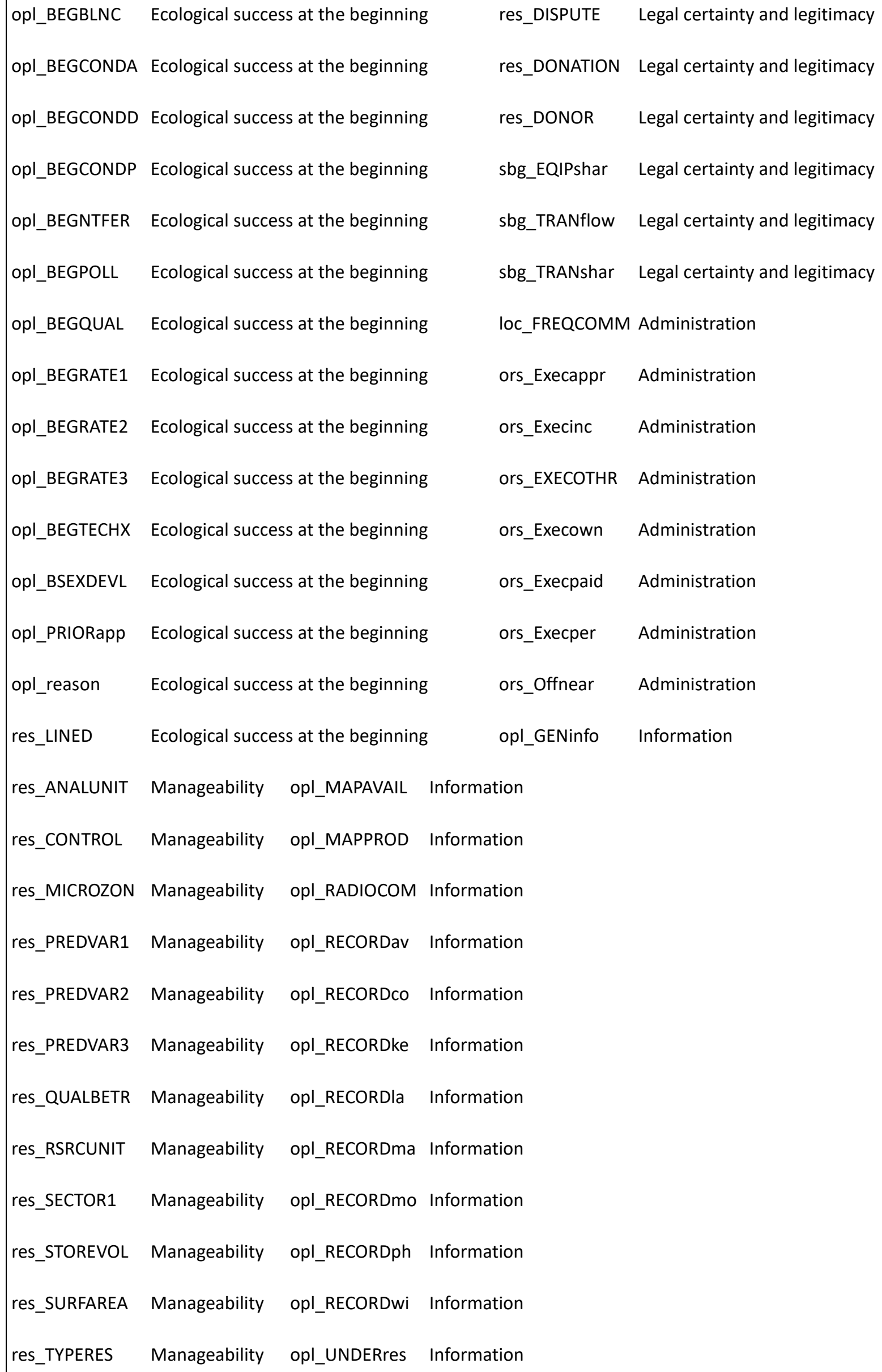




\begin{tabular}{|c|c|c|c|}
\hline res_VAROTIME & Manageability & \multicolumn{2}{|c|}{ opr_QUALUNIT Information } \\
\hline res_VARSPACE & Manageability & \multicolumn{2}{|c|}{ opr2_appmonit Information } \\
\hline res_VARYEAR & Manageability & \multicolumn{2}{|c|}{ opr2_appright Information } \\
\hline res_WATERORI & Manageability & \multicolumn{2}{|c|}{ opr2_appwork Information } \\
\hline sbg_ABSOQUAN & Regeneration of $\mathrm{RU}$ & opr2_condres & Information \\
\hline opl_BAVERAGE & Regeneration of $\mathrm{RU}$ & opr2_DEFinf & Information \\
\hline opl_EXTINCAP & Regeneration of $\mathrm{RU}$ & opr2_IOther & Information \\
\hline res_POTNTIAL & Regeneration of RU & opr2_numunit & Information \\
\hline sbg_OLSON & Regeneration of $\mathrm{RU}$ & opr2_physfact & Information \\
\hline sbg_SHARCHNG & Regeneration of $\mathrm{RU}$ & opr2_qassets & Information \\
\hline sbg_TECHEXTR & Regeneration of RU & opr2_unitflow & Information \\
\hline sbg_USERATE1 & Regeneration of $\mathrm{RU}$ & opr2_WRITTEN & Information \\
\hline sbg_USErate2 & Regeneration of $\mathrm{RU}$ & sbg_LITERACY & Information \\
\hline loc_NUMHOU & Number of actors & opl_aindictc & Characteristics of rules \\
\hline Ioc_NUMPOP & Number of actors & opr_CLEAR & Characteristics of rules \\
\hline opl_BNUMAPP1 & Number of actors & opr_DEFAGGR & Characteristics of rules \\
\hline opl_BNUMAPP2 & Number of actors & opr_EQSHARED & Characteristics of rules \\
\hline opl_BNUMTEM1 & Number of actors & opr_FIXNUM & Characteristics of rules \\
\hline opl_BNUMTEM2 & Number of actors & opr_MINSIZE & Characteristics of rules \\
\hline opl_Enumapp1 & Number of actors & opr_NARRANGE & Characteristics of rules \\
\hline opl_enumapp2 & Number of actors & opr_RTRANS2 & Characteristics of rules \\
\hline opl_ENUMTEM1 & Number of actors & opr_rulsetsb & Characteristics of rules \\
\hline opl_ENUMTEM2 & Number of actors & opr_RULSETSP & Characteristics of rules \\
\hline sbg_BNUMUSR1 & Number of actors & opr2_A10ther & Characteristics of rules \\
\hline sbg_BNUMUSR2 & Number of actors & opr2_A2Other & Characteristics of rules \\
\hline sbg_Enumusr1 & Number of actors & opr2_aggrrule & Characteristics of rules \\
\hline sbg_ENUMusr2 & Number of actors & opr2_apprtax & Characteristics of rules \\
\hline
\end{tabular}




\begin{tabular}{|c|c|c|c|c|c|}
\hline sbg_SNUMTEM1 & Number of act & & \multicolumn{2}{|c|}{ opr2_capinv } & Characteristics of rules \\
\hline sbg_SNUMTEM2 & Number of act & & \multicolumn{2}{|c|}{ opr2_DEFauth } & Characteristics of rules \\
\hline sbg_TEAMSIZE & Number of act & & \multicolumn{2}{|c|}{ opr2_easyund } & Characteristics of rules \\
\hline scr_SNUMapp2 & Number of act & & \multicolumn{2}{|c|}{ opr2_ELABsubs } & Characteristics of rules \\
\hline opl_CLANID & Group compos & ion & \multicolumn{2}{|c|}{ opr2_emerglab } & Characteristics of rules \\
\hline opl_Families & Group compos & ion & \multicolumn{2}{|c|}{ opr2_fixorder } & Characteristics of rules \\
\hline opl_RACEID & Group compos & ion & \multicolumn{2}{|c|}{ opr2_fixperc } & Characteristics of rules \\
\hline opl_SG1TOSG2 & Group compos & ion & \multicolumn{2}{|c|}{ opr2_fixtime } & Characteristics of rules \\
\hline opl_SG2TOSG3 & Group compos & ion & \multicolumn{2}{|c|}{ opr2_FLEXIBLE } & Characteristics of rules \\
\hline opl_SG3TOSG4 & Group compos & ion & \multicolumn{2}{|c|}{ opr2_freewith } & Characteristics of rules \\
\hline sbg_Sbgpdes & Group compos & ion & \multicolumn{2}{|c|}{ opr2_maintlab } & Characteristics of rules \\
\hline sbg_Scaste1 & Group compos & ion & \multicolumn{2}{|c|}{ opr2_ncycles } & Characteristics of rules \\
\hline sbg_SCLANID1 & Group compos & ion & \multicolumn{2}{|c|}{ opr2_RULEdur } & Characteristics of rules \\
\hline sbg_Scultvwr & Group compos & ion & \multicolumn{2}{|c|}{ opr2_rulsetsa } & Characteristics of rules \\
\hline sbg_Sethid1 & Group compos & ion & \multicolumn{2}{|c|}{ opr2_sploc } & Characteristics of rules \\
\hline sbg_Sgender1 & Group compos & ion & \multicolumn{2}{|c|}{ opr2_spseason } & Characteristics of rules \\
\hline sbg_Sgender2 & Group compos & ion & \multicolumn{2}{|c|}{ ors_Admlevel } & Characteristics of rules \\
\hline sbg_Slang1 & Group compos & ion & \multicolumn{2}{|c|}{ ors_Ruleclas } & Characteristics of rules \\
\hline sbg_Sothcomm & Group compos & ion & \multicolumn{2}{|c|}{ sbg_EQIPshar } & Characteristics of rules \\
\hline sbg_SRACEID1 & Group compos & ion & \multicolumn{2}{|c|}{ sbg_TRANflow } & Characteristics of rules \\
\hline sbg_Srelid1 & Group compos & ion & \multicolumn{2}{|c|}{ sbg_TRANshar } & Characteristics of rules \\
\hline opl_BEGTRUST & Social capital & opl & & Fairness & \\
\hline opl_ENDtrust & Social capital & opl & ALoser & Fairness & \\
\hline opl_GENRELtn & Social capital & opl & alyes & Fairness & \\
\hline opr2_howtran & Social capital & opl & equty & Fairness & \\
\hline opr2_LABorg & Social capital & opl & 1TOSG3 & Fairness & \\
\hline ors_Addserv & Social capital & opl & 1TOSG4 & Fairness & \\
\hline
\end{tabular}




\begin{tabular}{|c|c|c|c|c|}
\hline ors_Services & Social capital & opl_SG2TOSG4 & \multicolumn{2}{|l|}{ Fairness } \\
\hline res_WHOBUILT & Social capital & opl_WORSToff & \multicolumn{2}{|l|}{ Fairness } \\
\hline sbg_ENTACT & Social capital & opr_UNEQprib & \multicolumn{2}{|l|}{ Fairness } \\
\hline sbg_LISTPROB & Social capital & opr_UNEQPUN & \multicolumn{2}{|l|}{ Fairness } \\
\hline sbg_OFFSPRNG & Social capital & opr_UNEQrew & \multicolumn{2}{|l|}{ Fairness } \\
\hline sbg_Sbgpdes & Social capital & opr2_FAIR & \multicolumn{2}{|l|}{ Fairness } \\
\hline sbg_TEAMBASE & Social capital & opr2_UNEQduta & \multicolumn{2}{|l|}{ Fairness } \\
\hline sbg_TECHUSED & Social capital & opr2_UNEQpria & \multicolumn{2}{|l|}{ Fairness } \\
\hline opl_BRENTDIS & \multicolumn{3}{|c|}{ Dependency on resource ors_Expown } & Fairness \\
\hline opl_ERENTDIS & \multicolumn{3}{|c|}{ Dependency on resource sbg_MAINCONT } & Fairness \\
\hline loc_PERMPOP & \multicolumn{3}{|c|}{ Dependency on resource sbg_SUBvar } & Fairness \\
\hline opI_INSURANC & \multicolumn{3}{|c|}{ Dependency on resource opl_guard } & Control \\
\hline opl_insurdes & \multicolumn{3}{|c|}{ Dependency on resource opl_monpaid } & Control \\
\hline opl_Labor & \multicolumn{3}{|c|}{ Dependency on resource opl_OFFpgrd } & Control \\
\hline opl_labrdays & \multicolumn{3}{|c|}{ Dependency on resource opl_OffpNum } & Control \\
\hline opl_MAINTres & \multicolumn{3}{|c|}{ Dependency on resource opl_PEAKgrd } & Control \\
\hline opl_Penalty & \multicolumn{3}{|c|}{ Dependency on resource opl_PeakNum } & Control \\
\hline opr_PRICESUP & \multicolumn{3}{|c|}{ Dependency on resource opl_RLEVEL } & Control \\
\hline opr_SUMFEES1 & \multicolumn{3}{|c|}{ Dependency on resource opl_SELFmon } & Control \\
\hline opr_SUMFEES2 & \multicolumn{3}{|c|}{ Dependency on resource opl_USERseen } & Control \\
\hline opr_WAGEUSE & \multicolumn{3}{|c|}{ Dependency on resource opr_ADJOINFD } & Control \\
\hline ors_Fisource & \multicolumn{3}{|c|}{ Dependency on resource ors_Expown } & Control \\
\hline ors_Orgparag & \multicolumn{3}{|c|}{ Dependency on resource res_CONTROL } & Control \\
\hline res_IMPROVED & \multicolumn{3}{|c|}{ Dependency on resource opl_aindictc } & Compliance \\
\hline sbg_ALTSUPLY & \multicolumn{3}{|c|}{ Dependency on resource opl_BRIBERY } & Compliance \\
\hline sbg_ASSETS & \multicolumn{3}{|c|}{ Dependency on resource opl_MONsanct } & Compliance \\
\hline sbg_AVERinc & \multicolumn{3}{|c|}{ Dependency on resource opl_Penalty } & Compliance \\
\hline
\end{tabular}




\begin{tabular}{|c|c|c|c|}
\hline sbg_AVOIDhrm & Dependency on resource & opl_PHYsanct & Compliance \\
\hline Sbg_ENHANCE & Dependency on resource & opl_SOCsanct & Compliance \\
\hline sbg_FAMINCDE & Dependency on resource & opl_VARsanct & Compliance \\
\hline sbg_KPRESURE & Dependency on resource & opr_DEFpay & Compliance \\
\hline sbg_LONGvar & Dependency on resource & opr_FINES & Compliance \\
\hline sbg_OWNlabor & Dependency on resource & opr_INCARCER & Compliance \\
\hline sbg_SUBalt1 & Dependency on resource & opr_LOSEentr & Compliance \\
\hline sbg_SUBALT2 & Dependency on resource & opr_SHUNNING & Compliance \\
\hline sbg_sUBnot & Dependency on resource & opr2_LEGITIM & Compliance \\
\hline sbg_SUBSIM & Dependency on resource & ors_Enfrule & Compliance \\
\hline sbg_TEAMCAP & Dependency on resource & ors_Expown & Compliance \\
\hline opl_OTHRcoop & Dependency on group & sbg_RULEbrak & Compliance \\
\hline opr_shareorg & Dependency on group & sbg_RULEfoll & Compliance \\
\hline ors_Fisource & Dependency on group & sbg_RULquanc & Compliance \\
\hline ors_Orgparag & Dependency on group & sbg_RULtechc & Compliance \\
\hline sbg_ENTACT & Dependency on group & sbg_RULtimec & Compliance \\
\hline sbg_OFFSPRNG & Dependency on group & ors_Expown & Conflict management \\
\hline opl_NONapp & Group boundaries & res_CONFLICT & Conflict management \\
\hline opl_Numnon1 & Group boundaries & sbg_Sbgpdes & Conflict management \\
\hline opl_NUMnon2 & Group boundaries & sbg_VIOLENC1 & Conflict management \\
\hline opl_WELLdefn & Group boundaries & sbg_VIOLENC2 & Conflict management \\
\hline opr_AGE & Group boundaries & opr_LOSEentr & Exclusion \\
\hline opr_auction & Group boundaries & res_SHARED & Exclusion \\
\hline opr_BOther & Group boundaries & sbg_EXCLUDED & Exclusion \\
\hline opr_caste & Group boundaries & opl_BOWNCLOS & Exclusion \\
\hline opr_CITCOUNT & Group boundaries & opl_EOWNCLOS & Exclusion \\
\hline opr_citlocal & Group boundaries & opl_BAPCLOSE & Exclusion \\
\hline
\end{tabular}




\begin{tabular}{|c|c|c|c|}
\hline opr_CITSUBDI & Group boundaries & opl_EAPCLOSE & Exclusion \\
\hline opr_CLAN & Group boundaries & sbg_ACCESS & Exclusion \\
\hline opr_CLASS & Group boundaries & sbg_EXCLUDIN & Exclusion \\
\hline opr_conusage & Group boundaries & opl_NEWGROUP & Exclusion \\
\hline opr_DEFbound & Group boundaries & opl_EXTPOLL & Relations \\
\hline opr_DEMSKILL & Group boundaries & loc_RESCONF & Relations \\
\hline opr_ELIGIBLE & Group boundaries & opl_Bapclose & Relations \\
\hline opr_ENTRYFEE & Group boundaries & opl_Bownclos & Relations \\
\hline opr_ethnic & Group boundaries & opl_commlang & Relations \\
\hline opr_GENDER & Group boundaries & opl_Cultvwr & Relations \\
\hline opr_LEVEDUC & Group boundaries & opl_Eapclose & Relations \\
\hline opr_LICENSE & Group boundaries & opl_Eownclos & Relations \\
\hline opr_LICLIMIT & Group boundaries & opl_ethncid & Relations \\
\hline opr_lottery & Group boundaries & opl_Newgroup & Relations \\
\hline opr_organiza & Group boundaries & opl_NUMsubgp & Relations \\
\hline opr_OWNAPPRC & Group boundaries & opl_Othrcomm & Relations \\
\hline opr_ownland & Group boundaries & opl_relanims & Relations \\
\hline opr_ownright & Group boundaries & opl_sex & Relations \\
\hline opr_RACE & Group boundaries & opl_socstrat & Relations \\
\hline opr_RTRANS1 & Group boundaries & ors_Expother & Relations \\
\hline opr_RTRANS2 & Group boundaries & ors_Fisource & Relations \\
\hline opr_seasfee & Group boundaries & res_DESCRIPT & Relations \\
\hline opr_shareorg & Group boundaries & res_DISPUTE & Relations \\
\hline opr_shareres & Group boundaries & res_DONATION & Relations \\
\hline opr_unitsuse & Group boundaries & res_DONOR & Relations \\
\hline opr_USETECH & Group boundaries & res_IMPROVED & Relations \\
\hline sbg_Sbgpdes & Group boundaries & res_OFFNUM & Relations \\
\hline
\end{tabular}




\begin{tabular}{|c|c|c|c|}
\hline sbg_WELdefin & Group boundaries & res_PARENT & Relations \\
\hline opl_aindictc & Participation of users & res_PARNAME & Relations \\
\hline opl_ARENAS & Participation of users & res_WHOBUILT & Relations \\
\hline opl_ARENfreq & Participation of users & sbg_ACCESS & Relations \\
\hline opl_NEWOPRUL & Participation of users & sbg_Excludin & Relations \\
\hline opr_loccolch & Participation of users & sbg_OLSON & Relations \\
\hline opr2_regcolch & Participation of users & sbg_SUBwhere & Relations \\
\hline opr_RTRANS2 & Participation of users & IOC_ECONOLOC & Capabilities to adapt to change \\
\hline ori_Lev1Act & Participation of users & opl_INSURANC & Capabilities to adapt to change \\
\hline ori_Lev2Act & Participation of users & opl_insurdes & Capabilities to adapt to change \\
\hline ori_Lev3Act & Participation of users & opl_reason & Capabilities to adapt to change \\
\hline ori_OrgType & Participation of users & opr_EXTAID1 & Capabilities to adapt to change \\
\hline ors_Execappr & Participation of users & opr_EXTAID2 & Capabilities to adapt to change \\
\hline \multirow[t]{3}{*}{ ors_Expown } & Participation of users & opr_EXTAID3 & Capabilities to adapt to change \\
\hline & & sbg_LONGvar & Capabilities to adapt to change \\
\hline & & sbg_SUBvar & Capabilities to adapt to change \\
\hline
\end{tabular}




\section{LITERATURE CITED}

Adisa, O., J. Botai, A. Adeola, A. Hassen, C. Botai, D. Darkey, and E. Tesfamariam. 2019. Application of Artificial Neural Network for Predicting Maize Production in South Africa. Sustainability 11(4):1145.

Álvarez-Romero, J. G., R. L. Pressey, N. C. Ban, and J. Brodie. 2015. Advancing Land-Sea Conservation Planning: Integrating Modelling of Catchments, Land-Use Change, and River Plumes to Prioritise Catchment Management and Protection. PLoS ONE 10(12): 0145574.

Arima, E. Y. 2016. A Spatial Probit Econometric Model of Land Change: The Case of Infrastructure Development in Western Amazonia, Peru. PLoS ONE 11(3):e0152058.

Cao, C., S. Dragićević, and S. Li. 2019. Short-Term Forecasting of Land Use Change Using Recurrent Neural Network Models. Sustainability 11(19):5376.

Cenek, M., and M. Franklin. 2017. An adaptable agent-based model for guiding multi-species Pacific salmon fisheries management within a SES framework. Ecological Modelling 360:132-149.

Crespo, G. O., D. C. Dunn, G. Reygondeau, K. Boerder, B. Worm, W. Cheung, D. P. Tittensor, and P. N. Halpin. 2018. The environmental niche of the global high seas pelagic longline fleet. Science advances 4(8):eaat3681.

Ekasingh, B., and K. Ngamsomsuke. 2009. Searching for simplified farmers' crop choice models for integrated watershed management in Thailand: A data mining approach. Environmental Modelling \& Software 24(12):1373-1380.

Fan, Y., X. Jin, X. Xiang, Le Gan, X. Yang, Z. Zhang, and Y. Zhou. 2018. Evaluating and predicting the effectiveness of farmland consolidation on improving agricultural productivity in China. PLOS ONE 13(6):e0198171.

Frey, U. J., and H. Rusch. 2013. Using Artificial Neural Networks for the Analysis of SocialEcological Systems. Ecology and Society 18(2).

Frey, U. J., and H. Rusch. 2014. Modeling Ecological Success of Common Pool Resource Systems Using Large Datasets. World Development 59:93-103.

Gasche, L., S. Mahévas, and P. Marchal. 2013. Supporting fisheries management by means of complex models: Can we point out isles of robustness in a sea of uncertainty? PLoS ONE 8(10):e77566.

Gutiérrez, N. L., R. Hilborn, and O. Defeo. 2011. Leadership, social capital and incentives promote successful fisheries. Nature 470(7334):386-389.

Jouffray, J.-B., L. M. Wedding, A. V. Norström, M. K. Donovan, G. J. Williams, L. B. Crowder, A. L. Erickson, A. M. Friedlander, N. A. J. Graham, J. M. Gove, C. V. Kappel, J. N. Kittinger, J. Lecky, K. L. L. Oleson, K. A. Selkoe, C. White, I. D. Williams, and M. 
Nyström. 2019. Parsing human and biophysical drivers of coral reef regimes. Proceedings. Biological sciences 286(1896):20182544.

Jules Dreyfus-León, M. 1999. Individual-based modelling of fishermen search behaviour with neural networks and reinforcement learning. Ecological Modelling 120(2-3):287-297.

Keane, A., J. F. Lund, J. Bluwstein, N. D. Burgess, M. R. Nielsen, and K. Homewood. 2020. Impact of Tanzania's Wildlife Management Areas on household wealth. Nature Sustainability 3(3):226-233.

Li, J., B. Alvarez, J. Siwabessy, M. Tran, Z. Huang, R. Przeslawski, L. Radke, F. Howard, and S. Nichol. 2017. Application of random forest, generalised linear model and their hybrid methods with geostatistical techniques to count data: Predicting sponge species richness. Environmental Modelling \& Software 97:112-129.

Lindkvist, E., Ö. Ekeberg, and J. Norberg. 2017. Strategies for sustainable management of renewable resources during environmental change. Proceedings. Biological sciences 284(1850).

Little, L. R., and A. D. McDonald. 2007. Simulations of agents in social networks harvesting a resource. Ecological Modelling 204(3-4):379-386.

Magierowski, R. H., S. M. Read, S. J. B. Carter, D. M. Warfe, L. S. Cook, E. C. Lefroy, and P. E. Davies. 2015. Inferring landscape-scale land-use impacts on rivers using data from mesocosm experiments and artificial neural networks. PLoS ONE 10(3):e0120901.

Maldonado, A., D. Ramos-López, and P. Aguilera. 2018. A Comparison of Machine-Learning Methods to Select Socioeconomic Indicators in Cultural Landscapes. Sustainability 10(11):4312.

Mayfield, H., C. Smith, M. Gallagher, and M. Hockings. 2017. Use of freely available datasets and machine learning methods in predicting deforestation. Environmental Modelling \& Software 87:17-28.

Nguyen, K. A., W. Chen, B.-S. Lin, U. Seeboonruang, and K. Thomas. 2019. Predicting Sheet and Rill Erosion of Shihmen Reservoir Watershed in Taiwan Using Machine Learning. Sustainability 11(13):3615.

O'Farrell, S., J. N. Sanchirico, O. Spiegel, M. Depalle, A. C. Haynie, S. A. Murawski, L. Perruso, and A. Strelcheck. 2019. Disturbance modifies payoffs in the explore-exploit trade-off. Nature communications 10(1):3363.

Ouyang, Wang, and Zhu. 2019. Construction of the Ecological Security Pattern of Urban Agglomeration under the Framework of Supply and Demand of Ecosystem Services Using Bayesian Network Machine Learning: Case Study of the Changsha-Zhuzhou-Xiangtan Urban Agglomeration, China. Sustainability 11(22):6416.

Robinson, B., J. S. Cohen, and J. D. Herman. 2020. Detecting early warning signals of longterm water supply vulnerability using machine learning. Environmental Modelling \& Software 131:104781. 
Romulo, C. L., S. Posner, S. Cousins, J. Hoyle Fair, D. E. Bennett, H. Huber-Stearns, R. C. Richards, and R. I. McDonald. 2018. Global state and potential scope of investments in watershed services for large cities. Nature communications 9(1):4375.

Saputra, M. H., and H. S. Lee. 2019. Prediction of Land Use and Land Cover Changes for North Sumatra, Indonesia, Using an Artificial-Neural-Network-Based Cellular Automaton. Sustainability 11(11):3024.

Souza, R. A. de, and P. de Marco. 2018. Improved spatial model for Amazonian deforestation: An empirical assessment and spatial bias analysis. Ecological Modelling 387:1-9.

Václavík, T., S. Lautenbach, T. Kuemmerle, and R. Seppelt. 2013. Mapping global land system archetypes. Global Environmental Change 23(6):1637-1647.

Woo, S. Y., C. G. Jung, J. W. Lee, and S. J. Kim. 2019. Evaluation of Watershed Scale Aquatic Ecosystem Health by SWAT Modeling and Random Forest Technique. Sustainability 11(12):3397.

Yates, K. L., C. Mellin, M. J. Caley, B. T. Radford, and J. J. Meeuwig. 2016. Models of Marine Fish Biodiversity: Assessing Predictors from Three Habitat Classification Schemes. PLoS ONE 11(6):e0155634.

Zhang, J., D. Fu, C. Urich, and R. Singh. 2018. Accelerated Exploration for Long-Term Urban Water Infrastructure Planning through Machine Learning. Sustainability 10(12):4600. 


\title{
Code
}

The following code section shows the full code in $\mathrm{R}$ to produce 500 models for deep neural networks with the h2o software package. Data preparation, loading and saving models and results are part of the workflow, but are not specified in detail here, since these are user specific and not part of the core machine learning code.

\author{
\# Load libraries \\ library(data.table) \\ library(h2o) \\ \# Load data $=$ user+environment specific => empty
}

\# Initialise $\mathrm{H} 2 \mathrm{O}$

localH2O = h2o.init(nthreads=-1, min_mem_size $=$ "8196M", max_mem_size $=$ "20490M")

\# Convert to h2o

h2o_input $<-$ as.h2o(input)

\# Split 80:20

splits <- h2o.splitFrame(h2o_input, c $(0.80,0))$

train <- h2o.assign(splits[[1]], "train")

test <- h2o.assign(splits[[3]], "test")

\#\#\#\#\#\#\#\#\#\#\#\#\#\#\#\#\#\#\#

\# Set Hyperparameter \#

\#\#\#\#\#\#\#\#\#\#\#\#\#\#\#\#\#\#\# 
\# Produces architectures

number_architectures $<-20$

min_neurons $<-10$

max_neurons $<-500$

max_nr_layers $<-4$

hidden_opts = lapply $(1:$ number_architectures,

function(x) min_neurons + sample(max_neurons, sample(max_nr_layers),

replace $=$ TRUE)

\# Select range of learn rates

min_learnrate $<-0.01$

max_learnrate $<-0.30$

learnrate_stepsize $<-0.005$

learn_rate_opts <-seq(min_learnrate,max_learnrate, learnrate_stepsize $)$

\# Select range of epochs

min_epochs $<-50$

max_epochs <- 400

epoch_stepsize $<-5$

epochs_opts <- seq(min_epochs, max_epochs, epoch_stepsize)

\# Cross-validation number of folds

nfolds $<-5$

hyper_params $=$ list (

hidden $=$ hidden_opts 


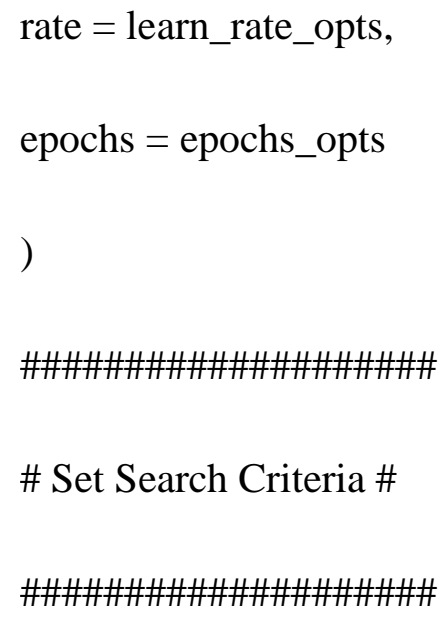

maxmodels $<-500$

search_criteria $=$ list (

strategy = "RandomDiscrete", \# "RandomDiscrete" vs "Cartesian" max_models $=$ maxmodels

)

\#\#\#\#\#\#\#\#\#\#\#\#\#

\# Grid Search \#

\#\#\#\#\#\#\#\#\#\#\#\#\#

\# Run model grid

dl_grid <- h2o.grid(

algorithm = "deeplearning",

grid_id = "dlgrid",

$\mathrm{x}=$ predictors,

$\mathrm{y}=$ response, 
training_frame $=$ train,

nfolds $=$ nfolds,

keep_cross_validation_predictions $=$ TRUE,

model_id = "dl_grid",

hyper_params $=$ hyper_params,

search_criteria $=$ search_criteria

)

\# Extracting and saving models and model results (user specific $=>$ not shown here)

\# Shut down the $\mathrm{H} 2 \mathrm{O}$ cluster:

h2o.shutdown $($ prompt $=$ FALSE $)$ 